\title{
O TUPI ANTIGO NO PORTUGUÊS: ALGUMAS QUESTÕES SOBRE HISTÓRIA, IDENTIDADE E ENSINO DE LÍNGUAGEM
}

\author{
THE ANCIENT TUPI IN PORTUGUESE: A FEW ISSUES ON \\ HISTORY, IDENTITY AND LANGUAGE TEACHING
}

"Tupi or not tupi, that is the question"

(ANDRADE, 1976)

\section{Marcos L.S. Góis* \\ Andérbio Márcio Silva Martins**}

\section{RESUMO}

Este texto apresenta algumas reflexões sobre a pluralidade linguística no Brasil, discutindo especificamente a contribuição do tupi antigo para o enriquecimento da variante brasileira da língua portuguesa e amplificando os debates em torno do ensino do empréstimo de línguas indígenas para singularizar a língua lusitana do aquém-mar. As discussões aqui empreendidas, com base em estudos da Linguística e da Sociologia críticas, têm por finalidade primeira fortalecer a tese de que, numa sociedade marcadamente mestiça, sua diversidade deve ser ensinada à população, favorecendo assim seu amadurecimento intelectual e cidadão ou, numa palavra, humano de seu povo. Desse modo, será possível contribuir para formar sujeitos capazes de ter, diante da diversidade, certa consciência da não existência da pureza linguística, cultural e social; aprender que as sociedades são complexas; aprender, enfim, as razões e os valores do que seja com-viver em sociedade.

Palavras-chave: educação linguística; ensino; tupi antigo; língua portuguesa.

\section{ABSTRACT}

This text presents some reflections on the linguistic pluralism in Brazil, specifically both discussing the contribution of old tupi for the enrichment of this Brazilian variant of the portuguese language and amplifying the debates on the teaching of the loan of indigenous languages to single out the cisatlantic Lusitanian language. The aim of the discussions here, based on studies of critical linguistics and sociology, is primarily to strengthen the thesis that in a society that is markedly interracial, its diversity must be taught to the population, thus favoring its intellectual, citizen or human maturation of its people. Thusly, it will be possible to contribute to forming individuals capable of having, before diversity, a certain awareness of the non-existence of linguistic, cultural and social purity; to learn that societies

\footnotetext{
* Universidade Federal da Grande Dourados (UFGD), Dourados, MS, Brasil. mlsgois2008@uol.com.br. ** Universidade Federal da Grande Dourados (UFGD), Dourados, MS, Brasil. anderbiomartins@ ufgd.edu.br.
} 
are complex; to learn, ultimately, the reasons and the values of what it is to live together in society.

Keywords: language education; teaching; old tupi; portuguese language.

\section{INTRODUÇÃO}

Sabemos há tempos que a língua é das referências mais marcantes no processo de identificação de um grupo social. Contudo, "Se a língua é um factor de identificação cultural, como se compreenda que uma língua viva em diferentes culturas?" (MATEUS, 2003). A conclusão de Mira Mateus, depois de percorrer um caminho que se inicia em Humboldt, passa pela Hipótese de Sapir-Whorf, por Noan Chomsky e por Steven Pinker, ilustrado com exemplos retirados do encontro entre línguas, é a seguinte:

[...] a actividade linguística de cada indivíduo contribui poderosamente para se reconhecer a si próprio e para ser reconhecido pelo outro. É na realidade um factor de identificação cultural, mas no uso, e pelo uso, que dela faz o indivíduo e não apenas por pertencer a uma das várias comunidades que a utilizam como materna. (MATEUS, 2003, p. 88).

Neste trabalho, tocamos nesse "encontro entre línguas". E o fazemos a partir de problematizações levantadas pela Sociologia Crítica, de modo particular, Boaventura de Sousa Santos (2002, 2002b, 2003), Santos e Nunes (2004), e, sobretudo, pelas discussões da Linguística Crítica, tal qual lemos em Kanavilill Rajagopalan (2006, 2009), Marcos Bagno e Egon Ragel (2005). Discutimos algumas questões de gramática e de ensino de língua, certamente, mas sem a pretensão de apresentar uma novidade. Nossa vontade é tão-somente contribuir para amplificar as vozes que clamam por tornar visível a diversidade linguística brasileira. E uma das formas de se alcançar isso é, no caso específico deste texto, pelo ensino de empréstimos de outras línguas ao enriquecimento da variante brasileira do Português.

Este ensaio diz respeito, portanto, à herança linguística Tupi na língua portuguesa, defendendo a importância de se ensiná-la, com o objetivo de contribuir para as discussões a respeito da diversidade linguística nacional e o ensino de línguas. Acreditamos que o preconceito tende a se arrefecer quando se (re)conhece a importância do outro, sua existência e sua contribuição para o eu existir; e só se (re)conhece o outro se a Educação for decisiva e enfática na formação de cidadãos conscientes de que a mistura entre culturas não é um descaminho social, pelo contrário, é-lhe constitutiva. Nesse sentido, só ampliando "o cânone do reconhecimento, da diferença e da igualdade" (SANTOS; NUNES, 2004, p. 5), dito de outro modo, só reconhecendo que somos inevitavelmente o resultado histórico da miscigenação, 
seremos capazes de colocar em prática a "educação linguística" de que tratam Bagno e Ragel (2005, p. 63); aquela que permite ao indivíduo "adquirir, desenvolver e ampliar o conhecimento de/sobre sua língua materna, de/sobre outras línguas, sobre a linguagem de um modo mais geral e sobre todos os demais sistemas semióticos".

Adiante, quando falarmos em língua Tupi, historicamente estaremos tratando da língua de contato entre os povos indígenas da Costa brasileira e os colonizadores portugueses; uma espécie de "língua geral", a qual José de Anchieta (1990) chamou de a "língua mais usada (ou falada) na costa do Brasil". Especificamente, o Tupi (às vezes dito Tupi-Guarani', raramente Tupinambá), que entrou no imaginário social brasileiro como "a" língua indígena por excelência, "foi a língua predominante nos contatos entre portugueses e índios nos séculos XVI e XVII e tornou-se a língua da expansão bandeirante no sul e da ocupação da Amazônia no norte" (RODRIGUES, 1994, p. 21). Conforme Aryon Rodrigues, por ser uma língua francamente usada pela população indígeno-luso-brasileira até o século XVIII, o governo português baixou um diretório proibindo amplamente seu uso e de qualquer outra língua que não a portuguesa. Trata-se do Diretório Pombalino, instituído em 1757 e revogado em 1798 (RODRIGUES, 1994; NOBRE, 2005).

Essa língua, apelidada "Língua Brasílica" (língua de intercâmbio), proporcionou aos povos uma interação cultural e, por que não, científica, uma vez que, a partir dela, os europeus puderam catalogar, registrar, documentar as coisas novas da "terra nova". Desse modo, à medida que foram, os colonizadores, se relacionando com o ambiente, a língua, como meio mais comum de comunicação - por sua vez, o mais eficiente - passou a ser uma necessidade natural. Daí, para o Tupi tornar-se de língua bárbara, como lhe rotulavam os primeiros europeus a chegar no século XVI, em "delicada, copiosa e elegante" (ANCHIETA, 1990, s.p.) foi um passo pequeno.

O desejo aqui é, modestamente, retomar algumas questões concernentes à natureza do empréstimo Tupi no Português brasileiro, sua importância para a consolidação de uma identidade Linguística brasileira² ${ }^{2}$, abordando também alguns

1. Conforme o Bacelar e Góis (1997, p. 107): "A ideia de uma única língua, o "Tupi-Guarani", que teria sido e/ou ainda é falado pelos índios brasileiros, faz parte do folclore linguístico nacional. [...]se tem consciência de que o Tupi-Guarani não foi e não é uma língua, mas uma família linguística, à qual se filiam aproximadamente 21 línguas vivas, algumas das quais, por sua vez, subdivididas em dialetos"

2. Há significativa presença de outras línguas, além das indígenas, que se amalgamam ao português do Brasil, sendo as de maior envergadura linguística as africanas. Para um estudo detalhado sobre isso, indicamos o texto A influência africana no português do Brasil (MENDONÇA, 2012). 
pontos relacionados ao ensino da própria língua portuguesa. Esperamos que este texto contribua para as discussões geolinguísticas em torno desse tema ${ }^{3}$.

\section{DA IDENTIDADE}

No parágrafo anterior afirmamos que a "Língua Brasílica" proporcionou uma interação científico-cultural, desde o século XVI, entre povos indígenas e os recémchegados colonizadores europeus. No sentido de discutir um pouco a natureza desta suposta "interação", nos indagamos sobre o momento de nossa história em que os povos indígenas foram vistos como parte formadora de nossa identidade étnica de brasileiros (ou mesmo linguística). Para responder à questão, acreditamos necessário fazer uma incursão a certa noção de "identidade".

Michel Debrun (1990) problematiza o sintagma "identidade nacional", afirmando que a relação entre os povos de um país nacional exige "um consenso em torno de certos valores, e uma diferença entre ele e outros tipos de consenso, ou entre eles e outros consensos nacionais. Ora, desde os fins do século XIX, muitos têm duvidado seja da coesão brasileira, seja da diferença específica do Brasil" (1990, p. 39).

Um ponto a destacar, presente nas indagações de Debrun, diz respeito a certo tipo de construção discursiva que aponta para a existência de um povo puro e uno. Isto é, discursivamente, há, no imaginário popular, o brasileiro (povo uno) e o estrangeiro (o do não-lugar ou o sem-lugar). A língua é, sem dúvidas, tópico relevante em qualquer discussão sobre identidade nacional, embora por posicionamento político possa ser escamoteada. Às vezes a língua aparece em estudos que tratam de identidades, como na citação de Mira Mateus, destacando sua relevância à construção, por exemplo, de uma identidade local, regional ou mesmo nacional. Existem, porém, enunciados que deixam escapar esta importância, e este é o caso da Lei 6.001/1973, conhecida como "Estatuto do Índio", que, em seu Artigo 39, exclui a língua do conjunto de elementos que compõe patrimônio indígena:

3. Kanavilil Rajagopalan afirma, em entrevista concedida ao jornal O popular (29/11/1999), ao tratar da relação língua, identidade e globalização, que "Identidade linguística basicamente é uma questão não mais linguística, mas sociológica, política" e que "O nacionalismo está surgindo de uma forma muito violenta em muitas partes do mundo. Esse nacionalismo é resposta a esse imperialismo que está em vigor. Muita gente acha que é só pasteurização, mas não é". Este trabalho quer servir, portanto, à discussão em voga. 
Art 39. Constituem bens do Patrimônio Indígena:

I - as terras pertencentes ao domínio dos grupos tribais ou comunidades indígenas;

II - o usufruto exclusivo das riquezas naturais e de todas as utilidades existentes nas terras ocupadas por grupos tribais ou comunidades indígenas e nas áreas a eles reservadas;

III - os bens móveis ou imóveis, adquiridos a qualquer título.

O ponto é que, quando colocamos em questão o intercurso entre indígenas e não indígenas ao longo da história nacional, há oficialmente apenas indícios de uma interação, muitas vezes apenas acessíveis aos estudiosos do assunto. Em síntese: historicamente, é uma interação falseada, por que oficialmente sem sujeitos interlocutores: raros indígenas do Brasil escreveram, em meio milênio, a história de seu povo e a própria, não tendo dado voz, portanto, a suas formas de ver e lidar com o mundo 4 . E quando aparecem nos escritos históricos, sejam eles verbais ou não, oficiais ou não, há um processo de objetificação de sua existência. Para Orlandi (1990, p. 56), "[no Estado brasileiro do sujeito branco], no que se refere à identidade cultural, o índio não entra nem como estrangeiro, nem sequer como antepassado". A mudança nesse paradigma só passa a ser realizada, de fato, com a promulgação da Constituição de 1988. Basicamente, até pouco tempo, os indígenas eram vistos na História do Brasil como povos que desempenharam papéis secundários, como se estivessem sempre agindo a partir da necessidade dos colonizadores. Em alguns momentos, foram vistos como amigos; em outros, como inimigos; como bons e como maus. E sempre como coadjuvantes na história dos colonizadores. Maria Regina Celestino de Almeida, em seu livro Os índios na História do Brasil, identifica três imagens dos povos indígenas nas análises sobre o período colonial: "idealizados no passado", "bárbaros do sertão" e "degradados" (ALMEIDA, 2010).

O primeiro grupo, "idealizados no passado", mostra a imagem de indígenas que foram enaltecidos nas pinturas, nos romances e nas músicas. O Guarani romântico criado por José de Alencar, por exemplo, foi utilizado na criação de um símbolo nacional. Sua imagem corresponde - convenientemente, segundo Cunha (1992) - ao "índio morto"; é o índio que aparece na história sem qualquer atitude de rebeldia ou de confronto, surge apenas como "aliado" dos portugueses, a quem devia submissão.

Esse olhar pode também ser identificado desde a criação, em 1838, do Instituto Histórico e Geográfico Brasileiro (IHGB), tendo em vista que, na tentativa de edificar um símbolo para incluir na memória coletiva da História do

4. Nesta discussão, que não aprofundaremos, cabem reflexões sobre a resistência ao discurso dominante, no sentido de que, no âmbito das ausências, dos silêncios, há formas de resistência. Dito de outro modo, na escrita da história do Brasil, embora os indígenas tenham sido deslocados para as margens, como veremos adiante neste texto, sua própria existência deixa marcas no discurso dominante. 
Brasil a presença indígena, mais uma representação de índio benevolente e aliado aos interesses dos colonizadores foi construída (ALMEIDA, 2010, p. 17).

O segundo grupo, os "bárbaros dos sertões", identificado por Almeida (2010, p. 140) correspondia aos indígenas que se rebelavam, ocupavam e atacavam a terra dos imigrantes e colonizadores. Contra esses índios "bárbaros", foram deliberadas as chamadas "Guerras Justas" (a partir de 1808, com a chegada da corte imperial ao Brasil). Podem ser ligados a esses indígenas os grupos Botocudos, Kaingáng, entre outros.

Ainda conforme Almeida (2010, p. 140-141), o terceiro grupo, "os degradados", é constituído por aqueles que sempre eram vistos como "misturados" e já integrados, ou em processo de integração à sociedade nacional, embora sempre vistos como preguiçosos. Cabe ressaltar que este grupo era formado por um menor número de indígenas, se comparado aos outros dois grupos citados.

Para o campo da História, a forma de ver os grupos indígenas modificou-se a partir do desenvolvimento do campo da História Cultural e do diálogo com outras áreas do conhecimento, aqui citamos principalmente a Antropologia. Para a mudança nessa concepção história, foi fundamental a ampliação do conceito de cultura, pois possibilitou a emergência de vozes de grupos marginalizados pelas práticas do discurso dominante que, por meio da consolidação da Nova História Cultural, começaram a se organizar e a lutar por espaço na história que lhes dizia respeito.

A cultura é de longa data objeto de estudo de historiadores, tendo sido intensificada a partir da metade do século XX. Se por um bom tempo o campo da cultura foi extremamente reduzido (apenas a "alta cultura", das obras literárias, das artes, etc., era proclamada como objetos da História), com a expansão do termo cultura, todos os atos do cotidiano passam também a ser objetos de estudos: "ao existir, qualquer indivíduo já está automaticamente produzindo cultura" (BARROS, 2010, p. 57). E nesse sentido podemos falar em "culturas linguísticas".

Desde os seus anos inicias do Brasil, houve um esforço de se apagar ou minimizar da história nacional as contribuições indígenas, seja no que diz respeito à diversidade (cultural, social, linguística) existente, seja em relação aos empréstimos linguísticos, tornando marginais as questões que as envolvem. Importa destacar, todavia, que pelo menos nos últimos 40 anos vem ocorrendo um forte movimento político em torno das culturas indígenas (OLIVEIRA, 1999), que muito contribui para problematizar a presença indígena na história brasileira. Atualmente, embora haja grupos linguísticos minoritários mobilizando-se para defender a própria língua, conscientes da importância de engajamentos políticos, ainda permanecem em pleno 
século XXI certos problemas no que tange a esses sujeitos. Algumas dessas questões concernentes ao ensino são apresentadas por D’Angelis (2012).

Não raro, como observa D’Angelis, as línguas indígenas são tratadas, ainda, como línguas estrangeiras na própria terra, a dizer que a política nacional para a educação em comunidades indígenas considera ensinar essas línguas indígenas (tal qual se ensina inglês, por exemplo, nas escolas públicas) para os próprios falantes dessas línguas, e não como "línguas de instrução". O autor mostra, como agravantes dessa situação, a "(i) não existência de livros de leitura e de disciplinas variadas, na língua indígena" 5 e "(ii) não existência de um planejamento linguístico adequado e programas específicos para o desenvolvimento das aulas de língua materna paras as diferentes séries" (p. 199). Sobre esses dois assuntos, pondera:

A primeira falta tem sérias consequências para a representação que a criança e o jovem indígena fazem da língua de sua comunidade. Alfabetizar-se na língua materna e, depois disso não encontrar utilidade ou ocasião relevante para uso dessa habilidade, tem o poder de marcar negativamente, com muita força, a imagem da língua indígena para os próprios falantes nativos. [...].

A segunda falta confirma e reforça a "inutilidade" da escrita em língua portuguesa, porque não lhe apresenta um lugar ou uso social relevante e porque não contribui para a construção da representação positiva da língua perante as novas gerações. (D'ANGELIS, 2012, p. 199).

A antropóloga Graciela Chamorro, renomada estudiosa do Guarani e suas variantes compreendidas e situadas na parte sul de Mato Grosso do Sul e Paraguai, dedicada à causa educacional, defende que

A mentalidade colonial e a ideologia da unidade nacional nos impuseram uma religião, uma cultura e uma língua. E nós interiorizamos acriticamente aspectos não muito exemplares do mundo ocidental e aprendemos a desprezar ou menosprezar os valores 'autóctones' das tradições locais e regionais. Neste contexto, as línguas e cosmologias indígenas, senão desapareceram fisicamente, sobreviveram e se desenvolveram como "clandestinas" ou "desaparecidas", à sombra de línguas e cosmologias supostamente universais. (CHAMORRO, 2007, p. 7).

Depreendemos daí que a clandestinidade e a não existência fazem-se sentir quando, no ensino da língua portuguesa e em outras práticas escolares, por exemplo, apagam-se ou marginalizam-se a contribuição de línguas não europeias para a formação desta língua materna: o Português brasileiro. Obviamente que, no registro da história, não se apagam ou marginalizam tão-somente aspectos do domínio linguístico, mas, sendo a língua o ponto nevrálgico do processo cultural,

5. Uma breve ressalva a esta afirmação: embora estejamos ainda muito distantes de uma solução satisfatória para os problemas apresentados por D'Angelis, há trabalhos escolares, didáticos inclusive, produzidos em línguas indígenas, inclusive relacionados à alfabetização. Alguns deles podem ser localizados nestes dois endereços: http://portal.mec.gov.br/secad/arquivos/pdf/ indigena/didatico indigena.pdf e http://lemad.fflch.usp.br/painel.mdi. 
atribuímos a ela um destaque. Ao dizer sobre esse apagamento dos indígenas da "consciência nacional", reforçamos que, "qualquer discurso que refira à identidade da cultura nacional já tem inscrita a exclusão do índio, necessariamente, como um princípio" (ORLANDI, 1990, p. 59).

O que estava em jogo na época do "descobrimento", dos primeiros estudos das línguas indígenas feitos por jesuítas, não era somente a questão religiosa, política, econômica, social, que envolvia o novo do "Novo Mundo". A problemática em torno das identidades foi marcadamente forte. De um lado, as referências dos colonizadores europeus brancos; do outro, a dos habitantes do "Novo Mundo". Inclusive, um exemplo relevante é o nome generalizador "índio", imposto pelos primeiros por causa de um suposto desvio. Sobre esse termo índio/ indígena, Westphalen (2007) pondera que, embora existam autores como Louis Owens e Gerald Vizenor que se oponham ao termo indian ("especialmente pela homonímia confusa indian (nativo-americano)/ indian (nativo da Índia)"), no caso brasileiro, diversos autores adotaram o termo generalizador "índio" e/ou "indígena" com orgulho. Westphalen alerta, contudo, que "nenhum dos termos é ou será considerado ideal, visto que a generalização peca sempre pelo apagamento de diferenças e peculiaridades de diferentes tribos" (p. 10) ${ }^{6}$.

Assim, durante muitos séculos, a visão que se teve (e ainda se tem, de " $\mathrm{n}$ " formas) dos primeiros habitantes destas terras era serem eles, todos, sem distinção, meramente "índios", com toda negatividade semântica que o termo ainda sustenta, principalmente quando de sua correlação com "bárbaros" e "selvagens". Aparentemente, desde então, por conta do suposto equívoco, tornaram-se estrangeiros na própria terra ${ }^{7}$. Cabe destacar, contudo, que a partir dos movimentos

6. Conferir, ainda, o texto de Bressa Freire (2002), no qual, discorrendo sobre cinco equívocos em relação ao termo "índio", afirma: "A primeira ideia que a maioria dos brasileiros tem sobre os índios é a de que eles constituem um bloco único, com a mesma cultura, compartilhando as mesmas crenças, a mesma língua. Ora, essa é uma ideia equivocada, que reduz culturas tão diferenciadas a uma entidade supra-étnica. [...]. Alguém aí pode objetar: - Ah, mas existe também "europeu" como uma denominação genérica que engloba vários povos de línguas e culturas diversas e ninguém questiona isso. É verdade. No entanto, quando um português ou um francês dizem que são europeus, essa denominação genérica não apaga a particular. Eles continuam sendo, cada um, português ou francês. No entanto, no caso do "índio", o equívoco está em que o genérico apaga as diferenças" (p. 4).

7. Este testemunho apresentando por Chamorro talvez nos ajude a ver a questão a partir de outro mirante: "Na década de 1980 e inícios de 1990, ao longo das discussões sobre educação escolar nas aldeias, ouvi líderes mbyá e guarani dos estados do Sul do Brasil dizerem que eles sabiam que o projeto histórico dominante no Brasil não os levava em conta, nem como iguais nem como diferentes. Nesta terra não havia lugar para a palavra indígena, assim como para outros setores marginalizados da população. Por perceber que não havia caminhos para sua palavra eles, muitas vezes, não diziam nada sobre as vicissitudes sociais que os expulsavam de seus lugares." (2007, p. 10). 
indígenas e indigenistas subsequentes a 1970, o que resultou numa Constituição que passou a garantir direitos aos indígenas, as diversas populações indígenas do país passaram a ter, em certa medida, visibilidade, o que não necessariamente cessou o preconceito e a discriminação; já não estão mais ocultos.

Em outros momentos (BACELAR; GÓIS, 1997; GÓIS, 2001), defendemos que o modo como discursivamente enunciamos (em primeiro, o branco; em segundo, o indígena) representa uma hierarquia de poder, historicamente constituída, em que o "índio" figura em posição discursiva subalterna. A posição discursiva subalterna não significa identidade subalterna. Mesmo porque "na identidade subalterna, a declaração da diferença é sempre uma tentativa de apropriar uma diferença declarada inferior de modo a reduzir ou a eliminar a sua inferioridade" e "Sem resistência não há identidade subalterna, há apenas subalternidade". (SANTOS, 2002, p. 46-47). Para que possamos construir a história por meio de diálogos, da interação entre sujeitos livres, é fundamental fazer emergir aquilo que marca nossa diferença, no caso do ensino de língua no Brasil, a inegável contribuição de línguas não europeias.

Orlandi (1990, p. 56.) apresenta uma perspectiva sobre o assunto que nos interessa, porque introduz uma componente que nos permite entender as origens históricas do apagamento aqui tratado: "Os portugueses descobriram o Brasil. Daí se infere que nossos antepassados são os portugueses e o Brasil era apenas uma extensão de terra". Os habitantes dessa "extensão de terra" não eram mais do que selvagens alienígenas que, descobertos, precisavam ser catequizados, domesticados, civilizados, porque não tinham nem rei, nem lei, nem fé, e isso significou, portanto, motivo para catequizar, administrar e governar.

Orlandi destaca que, a partir desse começo, os indígenas se tornaram alvos de um apagamento, não constituindo nada em si: "Esse é o seu estatuto histórico "transparente": não constam. Há uma ruptura histórica pela qual se passa do índio para o brasileiro através de um "salto" (1990, p. 56, grifo da autora). E foi, sem dúvida, a sobreposição, nunca pacífica, da cultura branca europeia sobre as culturas indígenas a origem desse apagamento. Importa rememorar que estamos sempre a falar de práticas identitárias: modos de vestir, de falar, de nomear, de comunicar, etc. É marcante e ilustrativa, nesse sentido, a seguinte passagem do Decreto pombalinos, publicado em 1758, que trata de aspectos linguísticos da colonização:

6. Sempre foi máxima inalteravelmente praticada em todas as Nações, que conquistaram novos domínios, introduzir logo nos Povos conquistados o seu próprio idioma, por ser indisputável, que este e um dos meios mais eficazes para desterrar dos Povos rústicos a barbaridade de seus

8. O decreto digitalizado está disponível: http://bd.camara.gov.br/bd/handle/bdcamara/1929\#. Acesso em: 05 jun. 2017. 


\begin{abstract}
antigos costumes; e tem mostrado a experiência, que ao mesmo passo, que se introduz nele o uso da Língua do Príncipe, que os conquistou, se lhes radica também o afeto, a veneração, e a obediência ao mesmo Príncipe. Observando, pois todas as Nações polidas do Mundo este prudente e sólido sistema, nesta Conquista se praticou tanto pelo contrário, que só cuidaram os primeiros Conquistadores estabelecer nela o uso da Língua, a que chamaram geral invenção verdadeiramente abominável e diabólica, para que privados os Índios de todos aqueles meios, que os podiam civilizar, permanecessem na rústica, e bárbara sujeição, em que até agora se conservavam. Para desterrar este perniciosíssimo abuso, será um dos principais cuidados dos Diretores, estabelecer nas suas respectivas povoações o uso da Língua Portuguesa, não consentindo por modo algum, que os meninos, e meninas, que pertencerem as Escolas, e todos aqueles Indios, que forem capazes de instrução nesta matéria, usem da Língua própria das suas Nações, ou da chamada geral; mas unicamente da Portuguesa, nas formas, que Sua Majestade tem recomendado em repetidas Ordens, que até agora se não observaram com total ruína Espiritual, e Temporal do Estado?.
\end{abstract}

Reconhecemos nesta fala de Pombal a lógica do dominante, ao hierarquizar a relação entre povos, declarando a imposição linguística como uma política necessária de dominação.

Da Semana de Arte Moderna de 1922, é possível trazer outros dois exemplos, demonstrando, por meio de dois enunciados que discutem bem a presençaausência dos indígenas no cenário nacional, como, em outro momento de nossa história, influenciado por revoluções artísticas e culturais, se tentou caracterizar supostas marcas das identidades dos povos indígenas no Brasil. O primeiro é um fragmento do Manifesto Antropófago, de Oswald de Andrade (1976), especialmente neste trecho bastante reverberado em trabalhos acadêmicos, que mostra o índio como um ser-outro: "Nunca fomos catequizados. Fizemos foi Carnaval. O índio vestido de senador do Império. Ou figurando nas óperas de Alencar, cheio de bons sentimentos portugueses". E fica mais bem caracterizada a ideia de apagamento do índio no livro Macunaíma, ao mostrar o índio como um não-ser: o herói sem nenhum caráter, de Mário de Andrade (1979), que evoca a figura de um índio amazônico que nasceu preto e virou branco - síntese do que se convencionou chamar de "povo brasileiro". Ou seja, é índio que não é índio; é negro e, depois, branco.

Se aceitamos que é principalmente nas culturas nacionais que se constrói uma identidade cultural (HALL, 2000), então qual a identidade cultural do brasileiro se não se localizarem nela as "marcas" da pluralidade étnica, cultural e, particularmente, linguística? Somos brasileiros, mas o que isso realmente significa? Em outros termos, o que nos identifica como pertencentes a uma "nação brasileira"? Hall diz que "as identidades nacionais não são coisas com as quais nós nascemos,

9. Disponível em: http://www.unicamp.br/iel/memoria/crono/acervo/tx7.html. Acesso em: 05 jun. 2017. 
mas são formadas no interior da representação" (2000, p. 48), afirmação com a qual concordamos, e continua deste modo:

\footnotetext{
As culturas nacionais, ao produzir sentidos sobre "a nação", sentidos com os quais podemos nos identificar, constroem identidades. Esses sentidos estão contidos nas estórias que são contadas sobre a nação, memórias que conectam seu presente com seu passado e imagens que dela são construídas. (p. 51).
}

Sem o reconhecimento dos elementos que a compõem, em outros, sem assumirmos efetivamente a mestiçagem como elemento fundador de nossa cultura (MUNANGA, 1999; RAMOS, 2004; SOUZA, 2007), a identidade nacional brasileira torna-se manca, fazendo com que os preconceitos pululem. A representação que se construiu dos povos indígenas, desde a Carta de Caminha, passando por toda escrita de José de Anchieta e demais documentadores, sejam eles missionários ou não, foi sempre edificada de modo a marginalizar/apagar, ocupando os indígenas no discurso do não indígena apenas uma posição figurativa: "cheio de bons sentimentos portugueses".

No próximo item, fazemos um exercício em torno da língua Tupi e sua relação com a Portuguesa, sem nos atrevermos a propor a solução para o problema levantado. Esperemos que as reflexões a seguir nos ajudem a pensar em propostas.

\section{ENSINO DE LÍNGUA PORTUGUESA: 0 CASO TUPI ANTIGO}

Um dos elementos que permite identificar um indivíduo a determinado grupo é a língua comum, por possibilitar ao sujeito se reconhecer e ser reconhecido, conjuntamente a outras manifestações culturais, como pertencente a um povo. As línguas guardam certa semelhança com organismos vivos: elas não estiveram sempre aqui e nada lhes garante um futuro. Elas têm uma origem, se desenvolvem, transformando-se na medida em que as condições de sua existência igualmente mudam, e, por fim, desaparecem, muitas vezes por não possuir tecnologia de registro como uma escrita, sem deixar rastros de que existiu. Conhecer, portanto, línguas é conhecer também os seres humanos que as usa(va)m... e, com eles, construir explicações sobre a nossa própria humanidade.

$\mathrm{Na}$ medida em que a rigor se dá pouca importância à contribuição da língua Tupi no ensino tradicional do Português, o que consideramos, pelo menos, um equívoco linguístico-pedagógico, contribui-se para alargar o fosso histórico criado quando da tentativa de construção de uma país monolíngue, e certamente as gramáticas normativas são o espaço no qual ainda reina a ideia de língua pura, 
uma "língua imaginária": "aquela idealização uniformizadora que paira sobre a diversidade concreta e fluida" (FARACO, 2016, p.176-177). Em praticamente todas as gramáticas normativo-descritivas disponíveis no mercado, por exemplo, o acervo lexical Tupi é tratado, não raro, como "tupinismos" (neste caso, leia-se "exótico"10).

Investigando algumas gramáticas normativas e descritivas brasileiras da língua portuguesa, verificamos que em muitas delas a contribuição ou é colocada em segundo plano, ou, na maioria das vezes, nem mencionada é. Em nenhuma parte das gramáticas de Cunha (1981), Cunha e Cintra (1985), Cegalla (1985) e Rocha Lima (1994), para ficar apenas em quatro nomes dos mais expressivos, há espaço (expressivo) para o Tupi. Em geral, abordam-se apenas questões pontuais, como nos exemplos de Cegalla (1985): "13 Do tupi: tatu, araponga, saci, piracema, Iracema, Itu", e Rocha Lima (1994): "4) Tupi: RANA: Caferana, sagarana" (p. 212) e "Hibridismos: árabe e tupi: caferana e tupi e Português: goiabeira" (p. 225). Mesmo mencionando, não há relevo em relação à contribuição Tupi, fruto dos avanços da área de linguística antropológica e sociolinguística, por exemplo. Pesquisando em algumas gramáticas e livros didáticos brasileiros do Português, o Tupi não recebe destaque algum.

A contribuição indígena para o enriquecimento da língua portuguesa no Brasil parece ser ignorada inclusive em livros didáticos dessa língua pátria, conforme observam Fargetti e Miranda (2016, p. 86):

[...] o descaso com a temática da diversidade linguística brasileira em materiais didáticos. $\mathrm{Na}$ grande quantidade de materiais pesquisados - aproximadamente cinquenta livros (de Português, História e Geografia) e vinte quatro Cadernos do Aluno, usados em escolas estaduais paulistas -, apenas dez se referem de alguma forma ao tema. Ao analisarmos estes dez materiais, percebemos que $60 \%$ trazem equívocos, geralmente relacionados às línguas gerais e aos seus surgimentos (a maioria deles afirma que foram "criadas" pelos jesuítas).

10. Rajagopalan (2009, p. 67) afirma que "a principal diferença, em termos práticos, entre uma língua "exótica" e uma língua "estrangeira" [...] está em que, no caso da primeira, nosso interesse em estudá-la se resume a uma curiosidade científica - o prazer de conhecer o estranho e o mítico ao passo que, no caso da segunda, somos motivados pelo desejo de ampliar os nossos horizontes culturais, de nos lançar a um nível melhor de vida $[\ldots]^{\prime \prime}$.

11. Em "goiabeira", mencionado como sendo tupi + português por Rocha Lima, comete-se um equívoco etimológico. Pela formação goiaba + -eira, sendo -eira um sufixo português, pressupõese que Rocha Lima considere o vocábulo "goiaba" como de origem Tupi. Entretanto, a palavra "goiaba" possui a seguinte etimologia, segundo Antônio Geraldo da Cunha (1998, p. 389): "Do taino de S. Domingos, com provável interferência do cast. guayaba". 
As gramáticas, os textos didáticos e paradidáticos ${ }^{12}$, a escola em seu todo, não podem deixar de trabalhar a influência Tupi (indígena no geral) sob os riscos de continuarmos a propagar o discurso de Marquês de Pombal, o de que indígenas e, por extensão, suas práticas são bárbaras, abomináveis, demoníacas. Como o padrão das gramáticas em geral não se presta ao estudo da língua, e sim a ditar as normas do bem falar e escrever, não é de se estranhar a ausência da língua Tupi nelas. Rocha Lima, mesmo modestamente, faz duas menções. Pouco, quase nada.

Mais um exemplo pode ser destacado das "Instruções" do antigo Formulário Ortográfico da Língua Portuguesa (FERREIRA, 1986, IX-X), aprovado em 12 de agosto de 1943, numa única referência indireta à etimologia "tupi-guarani", presente no capítulo XIV. Nesse Formulário, há o seguinte sobre o emprego do hífen: "Nos vocábulos formados por sufixos que representem as formas adjetivas como açu, guaçu e mirim, quando o exige a pronúncia e o primeiro elemento acaba e vogal acentuada graficamente: andá-açu, amoré-guaçu, anajá-mirim, capim-açu, etc.". A esse respeito, o novo Acordo Ortográfico, promulgado pelo Decreto N. 6.583, de 29 de setembro de 2008, diz:

$\left.3^{\circ}\right)$ Nas formações por sufixação apenas se emprega o hífen nos vocábulos terminados por sufixos de origem tupi-guarani que representam formas adjetivas, como açu, guaçu e mirim, quando o primeiro elemento acaba em vogal acentuada graficamente ou quando a pronúncia exige a distinção gráfica dos dois elementos: amoré-guaçu, anajá-mirim, andá-açu, capim-açu, CearáMirim.

O Tupi e o Português coexistindo no mesmo território produziram, ao longo da história, não só uma incalculável contribuição lexical de base Tupi, bem como variações diacrônicas, diatópicas e diastráticas de determinado termo genuinamente Tupi, que, portanto, transcendem às simples utilização do hífen. É o caso, por exemplo, de tatarana, taturana, mandorová, madruvá - entre outras - ao lado de criações portuguesas como bicho-cabeludo, lagarta-de-fogo, lagarta-cabeluda, gervão; etc.

Contudo, é importante salientar o seguinte: se desde os primeiros contatos entre colonizadores e povos da família Tupi, a língua portuguesa foi tomando por empréstimo palavras do léxico indígena para nomear a nova realidade e os novos itens culturais, o mesmo não se pode dizer, com plena certeza, do contrário, uma vez que o Tupi resistiu, significativamente, durante certo período, à incorporação de palavras portuguesas (BACELAR; GÓIS, 1997; GÓIS, 2001). Assim, por

12. Eduardo Navarro apresenta um plano de aula intitulado "Revele a influência do tupi no vocabulário brasileiro", que, embora simples e de pouca abrangência, é uma proposta que tentar preencher uma lacuna no ensino das contribuições linguísticas das línguas indígenas brasileiras. Disponível em: http://revistaescola.abril.com.br/ensino-medio/revele-influencia-tupi-vocabulariobrasileiro-431294.shtml. Acesso em: 15 abr. 2017. 
exemplo, o Português tomou do Tupi palavras como arapuca, abacaxi e tapioca para nomear novos dados, ou seja, "armadilha para pássaros", "uma espécie de fruto" e "certo tipo de bolo feito de mandioca", respectivamente. Os indígenas, ao também travarem contatos com os portugueses, estavam expostos a uma nova realidade e, consequentemente, a novos dados culturais. Para nomear esses dados, os indígenas recorreram muitas vezes, numa forma de resistir, ao próprio sistema linguístico, por meio de criações analógicas. Eis alguns exemplos ${ }^{13}$ :

1. a foice, para os indígenas, também era um novo dado cultural e, para nomeá-la, ao invés de tomar a palavra "foice" por empréstimo ao português, os índios tupi recorreram a um dado cultural existente e, por analogia, criaram uma expressão descritiva, configurando um neologismo na língua, como nos casos a seguir:

a. dado cultural existente: [i'ta] "machado de pedra" + característica analógica: [a'para] "torto", donde [ita'para] "machado torto" $=$ "foice" $=$ dado cultural novo ${ }^{14}$.

b. dados culturais existentes: [akay] "cabeça" + [aoß] "envoltório" + [uru'pe] "cogumelo", donde [akaygaoßuru'pe] "envoltório para a cabeça e forma de cogumelo" = "chapéu" $=$ dado cultural novo. (BACELAR $;$ GÓIS, 1997, p. 109)

Uma das mais marcantes contribuições Tupi para a formação da identidade linguística brasileira está em palavras híbridas, que se formaram ao longo destes cinco séculos, cuja base é um elemento Tupi, que possui fortes relações como outras manifestações socioculturais: música, dança, culinária, etc. Apresentamos apenas três casos paradigmáticos.

O primeiro é constituído por substantivos compostos em que pelo menos um dos lexemas é originário do Tupi e o(s) outro(s) do Português e/ou outras línguas. Como exemplo, cita-se sabiá-branco, composto de sabiá (do tupi) + branco (do germânico). O segundo caso diz respeito a substantivos cujos lexemas são todos Tupi ao passo que os morfemas derivacionais e flexionais são do Português. Tomemos o verbo empipocar, derivado do Tupi [pi'p ka], "estalando a pele", $+\{$ em\}$\{$-ar\}, afixos do Português. No terceiro caso, opera-se o processo inverso: a um lexema do Português, já oriundo de outra língua, soma-se um afixo de origem Tupi,

13. No trabalho citado, anotamos que a transcrição fonética é uma recriação hipotética com base em trabalhos do tupinólogo Aryon Dall'Igna Rodrigues $(1945 ; 1951)$ e do dicionarista Antônio Geraldo da Cunha (1998).

14. Aqui, sugerimos uma leve correção na análise feita por Bacelar e Góis: em lugar do que foi exposto em "a.", apontamos: "a. dado cultural existente: [i'ta] "pedra" + característica analógica: [a'para] "torto", resultando em [ita'para] "pedra torta", por analogia "machado torto" = "foice" $=$ dado cultural novo." 
como em canarana, composto de cana (do Latim) + o sufixo \{-rana $\}$ (do Tupi), "semelhante a".

Em língua portuguesa, a partir dos processos de formação de palavras, composição e derivação híbridas, verificamos que o léxico de base Tupi apresenta uma altíssima produtividade na formação de famílias de palavras, algumas das quais muito extensas, dado o significativo número de cognatos. Por exemplo, no Dicionário Aurélio Eletrônico - Século XXI (FERREIRA, 2001), encontram-se registrados 63 vocábulos compostos cuja base lexical é a palavra capim (do Tupi), "folha delgada", tais como: capim-amargoso, capim-bambu, capim-barba-de-bode, capim-santo, etc., além dos derivados: capinar, capina, capinador, capinzal, etc. Isso sem acrescentar os topônimos não dicionarizados, como Capim Branco (MG), Capim Grosso (BA), Capinópolis (MG), e os respectivos gentílicos, dicionarizados: capim-branquense, capim-grossense, capinopolino, etc.

Nos parágrafos anteriores, apresentamos certos fenômenos linguísticos do encontro entre línguas que poderiam resultar em atividades de ensino. Se mobilizados também conhecimentos da história, da geografia, da antropológica, etc., contribuiremos para criar um lócus interdisciplinar para a emergência de sujeitos conscientes da diversidade que moldam a existência de uma cultura. Não queremos, naturalmente, com estas poucas palavras e limitados exemplos, resolver uma questão que transcendem as esferas do linguístico e mesmo do discursivo. As relações de forças no campo político e educacional que determinam qual variedade de língua será a hegemônica, qual língua será aquela do conhecimento, da cultura, da religião, da política, da história... são o resultado de embates históricos.

Se consideramos que, numa sociedade efetivamente democrática, todos nós temos o direito à igualdade e à diferença (SANTOS, 2002b, p. 122), não nos parece impróprio afirmar: uma educação que não considere a pluralidade de conhecimentos numa sociedade, que não reconheça efetivamente sua diversidade linguística, que não reformule suas práticas escolares para dar conta da multiplicidade de sujeitos e de suas formas de ver o mundo, continuará reforçando um língua portuguesa imaginária.

\section{PALAVRAS FINAIS}

Não há como deixar de considerar as línguas indígenas brasileiras e africanas, com especial atenção dada à influência Tupi neste artigo, como parte formadora da identidade linguística e cultural brasileira. Está em nossa história. Afinal, sendo a contribuição Tupi uma das características linguísticas que tornaram a variante 
brasileira da língua portuguesa lexical e semanticamente distinta da lusitana, por que não resgatar tal importância, por que não a ensinar? No mínimo, os estudos e o ensino de língua portuguesa deveriam dar uma maior atenção às contribuições indígenas para a formação da identidade linguística e cultural brasileira.

Haveria, a rigor, formas de se ensinar a forte presença da língua (e da cultura) indígena (no caso específico deste trabalho, o Tupi) para a formação da identidade (linguística) brasileira. Pode-se ensinar ortografia, por exemplo. Podese trabalhar com nomes próprios de origem Tupi: Iara, Iracema, Ubirajara, etc.; cidades: Tupã, Itaquaquecetuba, Pindamonhangaba, Piracicaba, Umuarama, etc.; fauna: arara, jacaré, tucunaré, sucuri, etc.; flora: abacaxi, maçaranduba, açaí, guaraná, jabuticaba, pitanga, comida: paçoca, beiju, tapioca, pamonha. Enfim, o universo é amplo, e o desejo (querer fazer) parece ser o determinante para se conseguir incluir, no ensino, as contribuições indígenas, mas não como folclóricas, e sim históricas.

\section{REFERÊNCIAS}

ALMEIDA, Maria R. C. Os índios na bistória do Brasil. Rio de Janeiro: Editora FGV, 2010.

ANCHIETA, José de. Arte da gramática da língua mais usada na costa do Brasil. Edição fac-similar. São Paulo: Edições Loyola, 1990.

ANDRADE, Oswald de. O manifesto antropófago. In: TELES, Gilberto Mendonça. Vanguarda européia e modernismo brasileiro: apresentação e crítica dos principais manifestos vanguardistas. 3. ed. Petrópolis: Vozes; Brasília: INL, 1976.

ANDRADE, Mário. Macunaíma: o herói sem nenhum caráter. São Paulo: Martins, 1979.

BACELAR, Laércio Nora; GÓIS, Marcos L. S. A produtividade do léxico tupinambá no português do Brasil. Signótica. Goiânia-GO, v. 09, p. 105-118, 1997.

BRASIL. Decreto n. 6.583, de 29 de setembro de 2008. Promulga o Acordo Ortográfico da Língua Portuguesa, assinado em Lisboa, em 16 de dezembro de 1990. Disponível em: http://www.planalto.gov.br/ccivil 03/_Ato2007-2010/2008/Decreto/D6583. htm. Acesso em: 2 abr. 2017.

BAGNO, Marcos; RAGEL, Egon O. Tarefas da educação linguística no Brasil. Rev. Brasileira de Lingüística Aplicada, v. 5, n. 1, 2005. Disponível em: http://www.scielo.br/pdf/rbla/ v5n1/04.pdf. Acesso em: 20 abr. 2018. 
BARROS, José D’Assunção. O campo da bistória. Petrópolis: Vozes, 2010.

CEGALLA, Domingos Paschoal. Novíssima gramática da língua portuguesa. São Paulo: Nacional, 1985.

CHAMORRO, Graciela. Língua, Identidade e Universidade: pistas para uma experiência intercultural a partir do conceito guarani da palavra. In. Tellus, ano 7, n. 13, Campo Grande: UCDB, p. 37-40, 2007.

CUNHA, Antônio G. Dicionário etimológico (Nova Fronteira) da língua portuguesa. Rio de Janeiro: Nova Fronteira, 1997.

CUNHA, Antônio G. Dicionário bistórico de palavras portuguesas de origem tupi. 4. ed. São Paulo: Melhoramentos; Brasília: UnB, 1998.

CUNHA, Celso. Gramática do português contemporâneo. Belo Horizonte: Bernardo Alvares, 1981.

CUNHA, Celso.; CINTRA, Lindley. Nova gramática do português contemporâneo. Rio de Janeiro: Nova Fronteira, 1981.

CUNHA, Manuela C. da. Política indigenista no século XIX. In: (Org). História dos indios no Brasil. São Paulo: Companhia das Letras, 1992. p. 133-154.

D'ANGELIS, Wilmar da R. Aprisionando sonbos: a educação escolar indígena no Brasil. Campinas, SP: Curt Nimuendajú, 2012.

DEBRUN, Michel. A Identidade nacional brasileiro. Estudos Avançados, v.4, n. 8, São Paulo, jan./apr., 1990. Disponível em: < http://www.scielo.br/pdf/ea/v4n8/v4n8a04.pdf > . Acesso em: 21 out. 2013.

FARACO, Carlos Alberto. História sociopolítica da língua portuguesa. São Paulo: Parábola Editorial, 2016.

FARGETTI, Cristina M.; MIRANDA, Tayná G. Plurilinguismo: a diversidade que não é abordada nos livros didáticos. Letras Raras, Campina Grande - PB, v. 5, ano 5, n. 3, 2016. Disponível em: http://revistas.ufcg.edu.br/ch/index.php/RLR/article/ view/699. Acesso em: 15 jan. 2017

FERREIRA, Aurélio B. de H. Dicionário Aurélio Eletrônico. Rio de Janeiro: Nova Fronteira, 2001. 
FREIRE, José Ribamar B. Cinco idéias equivocadas sobre os índios. Disponível em: http:// www.nre.seed.pr.gov.br/patobranco/arquivos/File/Permanente/Educacao\%20 Indigena/Cinco.pdf. Acesso em: 21 abr. 2014.

GOIS, M. L. de S. O tupi no português brasileiro: a produtividade lexical. 2001. Dissertação (Mestrado em Linguística e Língua Portuguesa) - Faculdade de Ciências e Letras, UNESP. 2001.

HALL, Stuart. A identidade cultural na pós-modernidade. 4. ed. Rio de Janeiro: DP\&A, 2000.

MATEUS, Maria H. Mira. Se a língua é um factor de identificação cultural, como se compreenda que uma língua viva em diferentes culturas?. Revista de Letras, n. 25, Vol. 1/2 - jan/dez. 2003 Disponível em: < http://www.revistadeletras.ufc.br/rl25Art14. pdf >. Acesso em: 23 abr. 2014.

MENDONÇA, Renato. A influência africana no português do Brasil. Apresentação de Alberto da Costa e Silva; prefácio de Yeda Pessoa de Castro. Brasília: FUNAG, 2012.

MUNANGA, Kabengele. Rediscutindo a mestiçagem no Brasil: identidade nacional versus identidade negra. Petrópolis, RJ: Editora Vozes, 1999.

NAVARRO, Eduardo. Revele a influência do tupi no vocabulário brasileiro. Disponível em: http://revistaescola.abril.com.br/ensino-medio/revele-influencia-tupi-vocabulariobrasileiro-431294.shtml. Acesso em: 15 abr. 2013.

NOBRE, Domingos. História da educação escolar indígena no Brasil. 2005. Disponível em: http://www.aldeiaguaranisapukai.org.br/escola/artigo hist_educ indigena domingo nobre.pdf. Acesso em: 05 dez. 2015.

OLIVEIRA, Gilvan M. O que quer a linguística e o que se quer da linguística: a delicada questão da assessoria linguística no movimento indígena. Cadernos Ceres, n. 49: Educação Indígena e Interculturalidade. dez. 1999. p. 26-38

ORLANDI, Eni P. Terra à vista: discurso do confronto: velho e novo mundo. São Paulo/ Campinas: Cortez/Ed. da Unicamp, 1990.

RAJAGOPALAN, Kanavillil. Repensar o papel da Linguística Aplicada. IN: MOITA LOPES, Luiz Paulo da. Por uma linguística aplicada indisciplinar. 2. ed. São Paulo: Parábola, 2006.

RAJAGOPALAN, Kanavillil. Por uma linguística crítica: linguagem, identidade e a questão ética. São Paulo: Parábola, 2009. 
RAMOS, Arthur. A mestiçagem no Brasil. Tradução Waldir Freitas Oliveira. Maceió: UFAL, 2004. (Coleção Nordestina).

ROCHA LIMA, Carlos H. da. Gramática normativa da língua portuguesa. 32. ed. Rio de Janeiro: José Olympio, 1994.

RODRIGUES, Aryon D. Fonética histórica Tupi-Guarani: Diferenças fonéticas entre o Tupi e o Guarani. Arquivos do Museu Paranaense, Curitiba, v. 4, 1945, p. 333-354.

RODRIGUES, Aryon D. A composição em Tupi. Logos, Curitiba, ano 4, n. 14, 1951, p. 1-8.

RODRIGUES, Aryon D. Linguas brasileiras: para o conhecimento das línguas indígenas. São Paulo: Edições Loyola, 1994.

SANTOS, Boaventura de S. Entre Prospero e Caliban: colonialismo, pós-colonialismo e inter-identidade. In. RAMALHO, M. I.; RIBEIRO, B. (orgs.). Entre ser e estar: Raízes, percursos e discursos da identidade. Porto: Afrontamento, 2002. p. 23-85.

SANTOS, Boaventura de S. Reinventar a democracia. Lisboa: Fundação Maria Soares/Gradiva, 2002b. (Cadernos democráticos).

SANTOS, Boaventura de S. Para uma sociologia das ausências e uma sociologia das emergências. In. SANTOS, B. S. (Org.). Conbecimento prudente para uma vida decente: "Um discurso sobre as ciências" revisitado. Porto: Afrontamento, 2003. Disponível em: http://www.ces.uc.pt/bss/documentos/sociologia_das ausencias.pdf. 2003.

SANTOS, Boaventura de S.; NUNES, João A. Introdução: para ampliar o cânone do reconhecimento, da diferença e da igualdade. (Org.). Reconbecer para libertar: Os caminhos do cosmopolitismo cultural. Porto: Afrontamento, 2004.

SOUZA, Ricardo Luiz de. Identidade Nacional e Modernidade brasileira: o diálogo entre Sílvio Romero, Euclides da Cunha, Câmara Cascudo e Gilberto Freyre. Belo Horizonte: Autêntica, 2007.

WESTPHALEN, Flávia C. Survivance: a sobrevivência nas literaturas indígenas do canadá e do Brasil. 111 f. Dissertação (Mestrado em Letras). Porto alegre: Universidade Federal do Rio Grande do Sul. 2007.

Recebido: 10/10/2018

Aceito: 21/02/2019

Publicado: 29/03/2019 